\title{
Deep Seated Gliomas: Management and Surgical Outcome in a Series of 31 Patients Under Neuronavigation Guidance
}

\author{
RAMY TEAMA, M.D. and MOHAMED EMARA, M.D. \\ The Department of Neurosurgery, Faculty of Medicine, Benha University
}

\begin{abstract}
Background: Deep seated gliomas represent challenge to neurosurgeons as reaching these lesions may cause more harm than, application of neuronavigation lead to safe access and better results.
\end{abstract}

Aim of Study: Presentation of our experience in resection of deep seated gliomas using intraoperative neuronavigation at our department.

Patients and Methods: A prospective study including 31 cases with deep seated gliomas operated in our department in the period between January 2018 and December 2020. In all of these cases tumor was operated using intraoperative neuronavigation. This series included 18 males and 13 females.

Results: In 8 cases the tumor was basal ganglia, in 10 cases the tumor was located in the frontal lobe, in 7 cases the tumor was located in the parital lobe and in 6 cases it was located in the temporal lobe. Motor deficit was present in 15 cases, aphasia in 5 cases, fits occurred in 3 cases. In cases with lobar gliomas the approach was different according to tumor location and more than $90 \%$ removal was obtained in 19 cases and more than $70 \%$ removal in 4 cases. In cases with basal ganglia lesions different biopsies was obtained from core and margins. The most common pathology was glioblastoma in 21 cases.

Conclusion: Intraoperative neuronavigation is very valuable in resection of deep seated gliomas as it gives a chance to have multible biopsies from different locations in case of unoperable tumors, in operable cases it reduces morbidity by choosing a track that avoid eloquent brain areas in addition to proper flab localization.

Key Words: Deep - Glioma - Neuronavigation.

\section{Introduction}

NEUROSURGERY has been changed so much after the use of neuronavigation. Using neuronavigation in the field of neurosurgery has many benefits including better guidance, orientation and localization giving better results more safety and

Correspondence to: Dr. Ramy Teama, E-Mail: ramyteama82@gmail.com better outcome with better benefit to both the surgeon and patient [1].

Nuronavigation simultaneously represents a complex, multimodal, information-based, widely adaptable technique, method, or device using frameless stereotaxy for precise intraoperative guidance, orientation, and localization, with consequently much better intraoperative accuracy and the chance for preoperative virtual image simulation and postoperative analysis of the operative steps [1]

Introduction of neuronavigation revolutionized the field of neurosurgery. The benefits for the introduction of neuronavigation to neurosurgical field are truly variable, with the advantage to perform better guidance, orientation, and localization, and so give the surgeon a much better confidence and a better surgical outcome $[\mathbf{2 , 3 , 4}]$.

Glioma is the commonest tumor between central nervous system tumors; surgery is difficult in such lesions especially when deep seated or near eloquent areas of the brain as surgery represents a great threatening to vital structures close to the tumor. Intraoperative magnetic resonance imaging (iMRI), multimodal neuronavigation may prove beneficial during surgery. The deep seated gliomas is an obstacle against complete resection; surrounding brain tissue can be injured, leading to hemiplegia, aphasia, coma, and others. The amount of removed tumor has direct effect on the clinical outcome. With the development of electrophysiological monitoring, imaging, and microsurgery, better results can now be obtained during surgical resection of glioma. The use of intraoperative neuronavigation enables the accurate localization of lesions during surgery, much improving microneurosurgical results. Multible factors have negative effect on the accuracy of navigation including operation error, shifting of registration system, and intraoperative brain tissue shift (brain shift) [5]. 
The extent of tumor resection is the most important factor for better tumor control and better surgical outcome. Intraoperative neuronavigated microsurgery using MRI proofed to be a useful neuroimaging technique for better and safe tumor resection while reducing operative damage to the surrounding normal brain reducing complications and improving survival [6].

\section{Patients and Methods}

Thirty one patients with known deep seated glioma were operated upon at our university hospitals in the period between January 2018 and December 2020. We performed this prospective study to present our experience in resection of deep seated gliomas using intraoperative neuronavigation system at our Neurosurgery Department at Benha University Hospitals. Inclusion criteria included any patient with deep seated glioma with or without neurological deficit with full clinical, radiological, complete follow-up and contact data. Approval of the ethical comitte in our university was obtained. Exclusion criteria are patients with contraindications to general anaethesia and those with superficialy located glioma.

During this period 31 patients met the inclusion criteria, full clinical radiological and follow-up data were studied carefully and all patients were formally consented before surgery.

All patients were subjected to detailed general and neurological examination, contrast enhanced magnetic resonance imaging (MRI) of the brain. Tumor characteristics, tumor size measured in $\mathrm{mm}$ were reported. Routine laboratory investigations were done for all cases. The neurological status of patients was recorded carefully. Operative data were reported with special attention given to type of anesthesia, time of surgery and intraoperative complications if present. MRI brain navigation protocol was done one night before surgery for all cases. Detailed neurological examination was performed in all cases after full recovery, then daily till discharge from the hospital. CT brain was done the second day after surgery to assess for extent of removal and possible complications.

\section{Results}

\section{Demographic data:}

We operated on 31 cases 20 of them were females while 11 were males, the youngest was 51 the oldest was 63 years, the mean age was $56 \pm 3.7$. The mean duration of complain was $8.2 \pm 3.9$ months (range, 2-18 months). The main symptom was headache that was present in 29 cases, of these 7 cases present with headache like migraine $\& 4$ cases present with headache like tension headache. Hemiplegia was present in 4 cases and was evident in the upper limb more than the lower limb. Hemiparesis was present in 11 cases. Dysphasia was present in 5 cases, three of these cases were associated with motor deficit all of them were left sided. Convulsions occurred in 3 cases. The tumor was discovered accidentally in 3 cases (mild headache, migraine, after trauma).

The mean preoperative karnofsky performance score (kps) was 80 (ranged from 50-100), in our series cases with high grade glioma had more neurological deficit and lower KPS while the three cases with fits had oligoastrocytoma.

Radiologically in 8 cases $(25.8 \%)$ the tumor was basal ganglia, in $10(32.25 \%)$ cases the tumor was located in the frontal lobe, in 7 cases $(22.58 \%)$ the tumor was located in the parital lobe and in the remaining 6 cases $(19.35 \%)$ it was located in the temporal lobe. Glioblastoma was suspected in 21 cases $(67.74 \%)$, cases with high grade glioma were ring enhancing with cystic component in most cases however 3 cases with solid component and little contrast enhancement were proved latter to be glioblastoma. The tumor infiltrated the ventricular system in 5 cases $(16.1 \%) 3$ of them were lobar, and the corpus callosum in 3 cases $(9.67 \%)$.

Neuronaviagtor was used in all cases, in basal ganglionic lesions neuronavigation was used to aid us to have biopsy from the lesion; it gives us the shortest track while avoiding injury of eloquent areas. In lobar lesions transcortical approach was used in all cases, neuronavigation was used to design the flab to directly access the tumor without passing through eloquent areas of the brain, it also gave us an idea about the extent of tumor resection during surgery. We opened the lateral ventricle in 3 cases with lobar glioma to remove as much as possible of the tumor. More than $90 \%$ removal was obtained in 19 cases and more than $70 \%$ removal in 4 cases in these 4 cases the tumor invaded the basal ganglia or invasion of the corpus callosum was present. In cases with basal ganglia lesions different biopsies was obtained from core and margins. Recurrence of lobar glioma during 12 months of follow up occurred in 3 cases, reoperation was performed for two of them while in one patient reoperation was not possible due to bad general condition. In our series there was no reported intraoperative morbidity or mortality. 


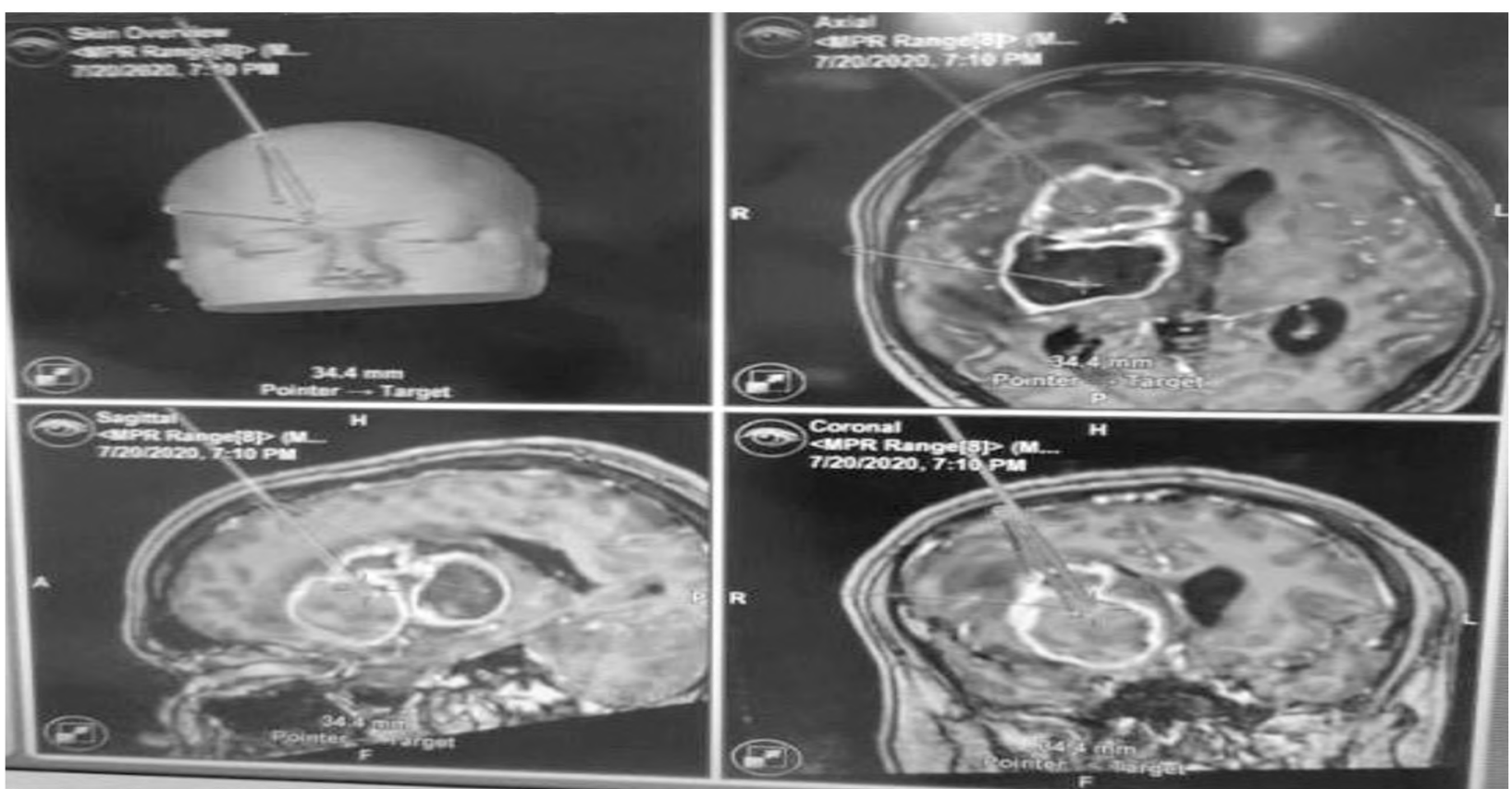

Fig. (1): A case of deep seated glioma located in the right basal ganglia, multible biopsies were taken and proved later to be glioblastomamultiforme.

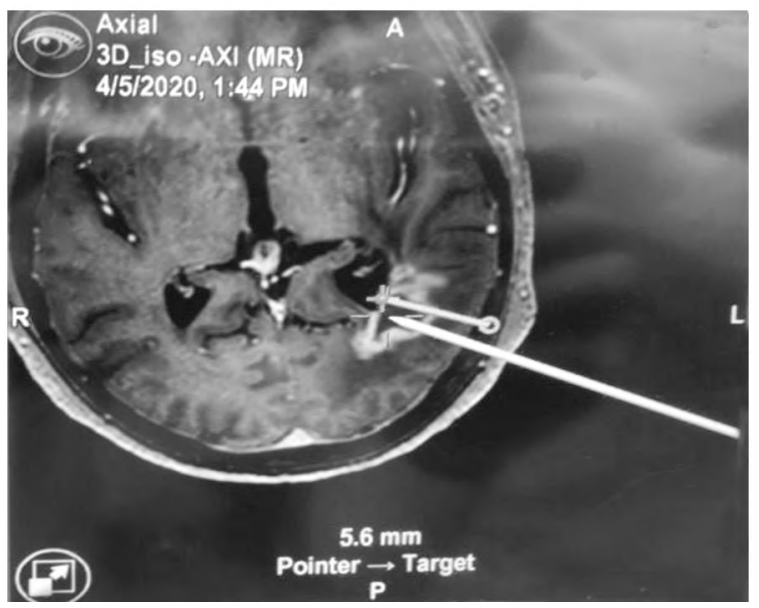

Fig. (2): A case of left occipital deep seated glioma extending to the left lateral ventricle, gross total removal was done, the lateral ventricle was reached with no csf leak postoperative.

\section{Pathological results:}

According to pathological evaluation glioblastoma was present in 21 cases, astrocytoma grade III in 7 cases and oligoastrocytoma in 3 cases. The two cases with recurrence transformed from astrocytoma grade III to glioblastoma.

\section{Clinical outcome:}

Preoperative Hemiparesis was present in 11 cases, worsened hemiparesis up to hemiplegia occurred in 5 cases (frontal \& parital), during one month of follow-up 4 of them showed improvement while one case remained hemiplegic. Dysphasia also was present in 5 cases all of them had left sided lesions, two of them showed progressive dysphasia postoperative then improved at 1 month of follow-up. Headache showed marked improvement in most cases, only 9 cases had co of headache postop 5 of them needed medical treatment. Postoperative seizures developed in 5 cases postop including the three cases with initial seizures, 4 of them were controlled on antiepileptics while one cases was severe and we added 2 nd line antiepileptic to controle. Intracerebral hematoma in the tumor bed occurred in 3 cases with extension to the lateral ventricle in one of them, gradual resolution over 2 weeks occurred in the 3 cases \& no one of them necessitates surgical intervention.

Table (1): Postoperative outcome.

\begin{tabular}{|c|c|c|}
\hline Event & Preoperative & Postoperative \\
\hline Hemiparesis & $11(35.48 \%)$ & $\begin{array}{l}-6 \text { cases (no change) } \\
\quad(19.35 \%) \\
-1 \text { case (wose) }(3.2 \%) \\
-4 \text { (improved but still } \\
\text { hemiplegic) }(12.8 \%)\end{array}$ \\
\hline Hemiplegia & $4(12.8 \%)$ & $-4(12.8 \%)$ \\
\hline Dysphasia & $5(16.1 \%)$ & $\begin{array}{l}-2 \text { improved }(6.45 \%) \\
-3 \text { cases (no change) } \\
\quad(9.67 \%)\end{array}$ \\
\hline Headache & $29(93.5 \%)$ & $11(35.5 \%)$ \\
\hline Seizures & $3(9.67 \%)$ & $5(16.1 \%)$ \\
\hline Postop. Hematoma & - & $3(9.67 \%)$ \\
\hline Recurrence & - & $3(9.67 \%)$ \\
\hline Subtotal Removal & - & $23(74.1 \%)$ \\
\hline Biopsy & - & $8(25.8 \%)$ \\
\hline
\end{tabular}



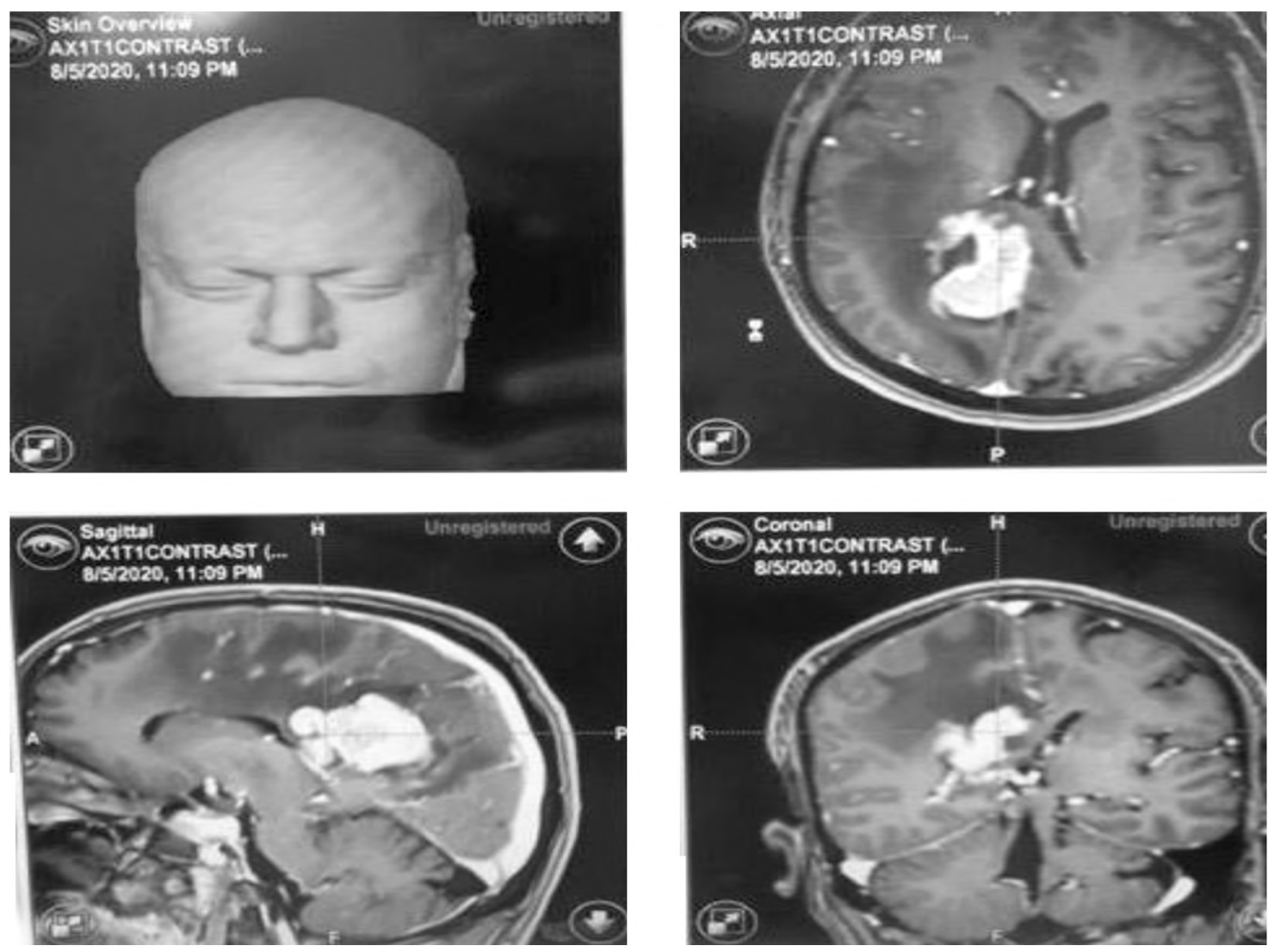

Fig. (3): A case of right posterior parital glioma with infiltration of the corpus callosum that limits the excision of the lesion.

\section{Discussion}

"Maximally remove tumors, minimally impair neurological function" is the driving principle of an effective glioma surgery. Evidence-based medicine has shown that for patients with an intracranial tumor, maximum removal the tumor results in the least neurological deficits and an increased of the patients' lifetime with less morbidity [7,8]

Lehe \& Scharam performed a study including 34 cases with cingulate gyrus glioma most of them were deep with cortical extension to the frontal or parital lobes. In this study the main presenting symptom was fits (61\%). In this study the author used interhemispheric approach $29 \%$ of cases \& transcortical approach in $71 \%$ of cases. Electrophysiological monitoring was used in $69 \%$ of cases $\&$ neuronavigation was used in $39 \%$. Resection of more than $90 \%$ of the tumor mass was performed in $84 \%$ of cases. In this study low grade glioma occurred in $29 \%$ of cases, GBM in $26 \%$ of cases \&oligoastrocytoma in 245 of cases. In this study $34 \%$ had transient supplementary motor area syndrome. Opening the lateral ventricle occurred in 18 cases $\&$ redo surgery was performed in 4 cases [9].
Zhou et al., conducted a study to evaluate the value of intraoperative magnetic resonance imaging (iMRI) combined with neuronavigation for the resection of insular gliomas. This study include 41 operated patients with deep insular glioma with the aid of intraoperative neuronavigation \& intraoperative MRI. The authors achieved gross total resection in 16 patients (39\%) subtotalresction in 18 patients $(44 \%) \&$ partial resection in 7 cases (17\%). The authors concluded that intraoperative neuronavigation when compined with surgery can maximize the outcome and benefits of surgery [10]

Lu et al., performed another study including 40 patients with glioma in eloquent areas, they divided patients into two groups, the first group included 20 cases operated using intraoperative MRI, the second group included 20 patients operated using intraoperative neuronavigation. Upon comparison of the two groups they found that the resection rate is higher in cases operated using intraoperative MRI $(96.55 \pm 4.03 \%$ vs $87.70 \pm$ $10.98 \%, p=.002)$, they also found that the incidence of neurological deficit is lower in the group operated using intraoperative MRI but the disadvantage of intraoperative MRI is the longer operative time [5]. 


\section{Conclusion:}

intraoperative neuronavigation is very valuable in resection of deep seated gliomas as it gives a chance to have multible biopsies from different locations in case of unoperable tumors, in operable cases it reduces morbidity by choosing a track that avoid eloquent brain areas in addition to proper flab localization, so in these cases we think that the use of neuronavigation is valuable.

\section{References}

1- ENCHEV Y.: Neuronavigation: Geneology, reality, and prospects. Neurosurg Focus, Vol. 27 (3): E1, 2009.

2- CHEV Y., BOZINOV O., MILLER D., TIRAKOTAI W., HEINZE S., BENES L., et al.: Image-guided ultrasonography for recurrent cystic gliomas. Acta. Neurochir (Wien), Vol. 148: pp. 1053-1063, 2006.

3- ENCHEV Y.P., POPOV R.V., ROMANSKY K.V., MARINOV M.B. and BUSSARSKY V.A.: Role of neuronavigation in the resection of intracranial arteriovenous malformations. Folia Med. (Plovdiv), Vol. 50: pp. 40-45, 2008.

4- OI S. and ENCHEV Y.: Neuro endoscopic for aminalplasty of foramen of Monro. Childs Nerv. Syst., Vol. 24: pp. 933-942, 2008.
5- LU C.Y., CHEN X.L., CHEN X.L., FANG X.L. and ZHAO Y.L.: Clinical application of 3.0 T intraoperative magnetic resonance combined with multimodal neuronavigation in resection of cerebral eloquent area glioma. Observational Study Medicine (Baltimore), Vol. 97 (34) e 11702, 2018.

6- LEROY H.A., TULEASCA C., MICHEL Q.V. and REYNS N.: Intraoperative MRI guidance for right deep fronto-temporal glioma resection: How I do it. Acta. Neurochir (Wien), Vol. 162 (12): pp. 3037-3041, 2020.

7- McGIRT M.J., CHAICHANA K.L. and ATTENELLO F.J.: Extent of surgical resection is independently associated with survival in patients with hemispheric infiltrating low-grade gliomas. Neurosurgery, Vol. 63: pp. 700-714, 2008.

8- SANAI N., POLLEY M.Y. and BERGER M.S.: Insular glioma resection. assessment of patient morbidity, survival, and tumor progression. J. Neurosurg., Vol. 112: pp. 1-9, 2010.

9- LEHE M. and SCHARAM J.: Gliomas of the cingulate gyrus. surgical management and functional outcome. Neurosurg Focus, Vol. 27 (2): E9, 2009.

10- ZHOU Q., XIA L., HE K., YAN S., XU X., LI X., et al. Application of intraoperative MRI combined with neuronavigation in microsurgical resection for insular glioma. J. Cent. South Univ. (Med. Sci.), Vol. 43 (4): pp. 383 387, 2018.

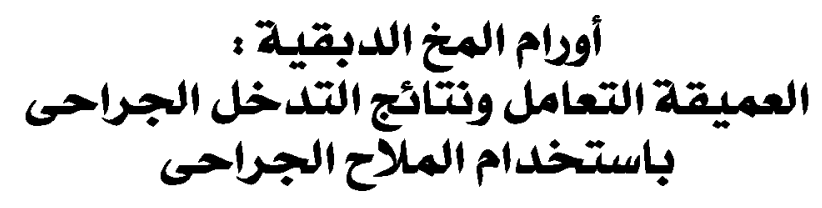

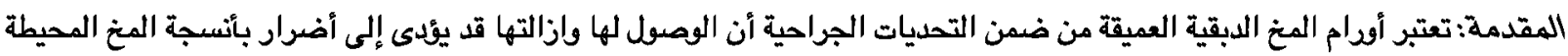

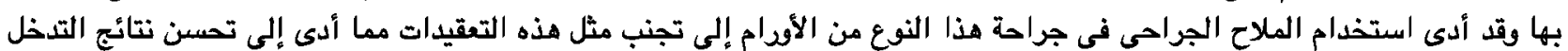
الجراحي. الهدف من الدراسة: تقديم نتائج خبرتنا الجراحية فى مثل هذا النوع من الأودام باستخدام الملاح الجراحى فى قسم جراحة المخ والأعصاب بطب بنها. تصميم الدراسة: دراسة وصفية إكلينيكية مستقبلية.

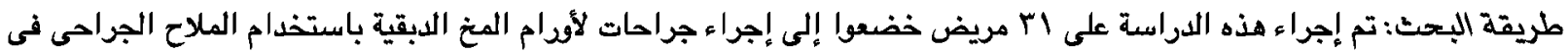

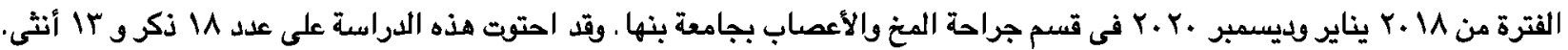

$$
\begin{aligned}
& \text { النتائج: كان الورم موجوداً في علد ^ حالات في العقد القاعدة، وقد تم أخذ عينات متعددة من هذه الأورام. وقد وتواجد الورم في +1 حالات }
\end{aligned}
$$

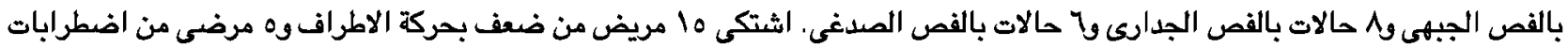

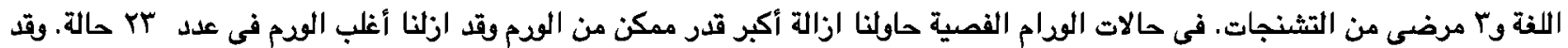

$$
\begin{aligned}
& \text { كان الورم الأكثر شيوعاً الودم الديقى متعدد الأشكال. }
\end{aligned}
$$

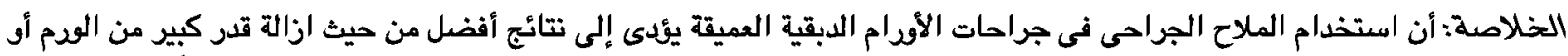

$$
\begin{aligned}
& \text { أخذ عينات من مختلف مواقع الورم مع تجنب إصابة أنسجة ومراكز المخ المحيطة بالودم عن طريق أختيار المدخل الأقل ضرداً. }
\end{aligned}
$$

